\title{
Selective Inhibition of NF-kappa-B with NBD Peptide Reduces Tumor- Induced Wasting in a Murine Model of Cancer Cachexia In vivo
}

\author{
Ashley Wysong ${ }^{1,2}$, Scott A. Asher ${ }^{3}$, Xiaoying Yin ${ }^{3,8}$, Mitchell R. Gore ${ }^{3}$, Lisa Weinstein ${ }^{5}$, Denis C. Guttridge ${ }^{6}$, Albert S. Baldwin $^{7,8,9}$, \\ Marion E. Couch ${ }^{3,8}$ and Monte S. Willis ${ }^{4,5 *}$
}

${ }^{1}$ Duke University School of Medicine, Durham, North Carolina

${ }^{2}$ Howard Hughes Medical Institute Medical Research Training Fellow, The Lineberger Comprehensive Cancer Center, Chapel Hill, North Carolina.

${ }^{3}$ Department of Otolaryngology-Head and Neck Surgery, University of North Carolina School of Medicine, Chapel Hill, North Carolina

${ }^{4} \mathrm{McAllister}$ Heart Institute, University of North Carolina at Chapel Hill, Chapel Hill, North Carolina

${ }^{5}$ Department of Pathology \& Laboratory Medicine, University of North Carolina, Chapel Hill, North Carolina

${ }^{6}$ Division of Human Cancer Genetics, Department of Molecular Virology, Immunology and Medical Genetics, Integrated Biomedical Graduate Program, Department of

Pathology, and The Arthur G. James Comprehensive Cancer Center The Ohio State University, Columbus, Ohio

${ }^{7}$ Curriculum in Genetics and Molecular Biology, Department of Biology, University of North Carolina at Chapel Hill, Chapel Hill, NC

${ }^{8}$ Lineberger Comprehensive Cancer Center, University of North Carolina at Chapel Hill, Chapel Hill, North Carolina

${ }^{9}$ Theralogics, Inc. Chapel Hill, North Carolina

\begin{abstract}
Cancer cachexia is a severe wasting syndrome characterized by the progressive loss of lean body mass and systemic inflammation, which is seen in as many as $80 \%$ of patients with advanced malignancy. It accounts for an estimated $20-30 \%$ of all cancer-related deaths. The mechanism by which cancer induces skeletal muscle atrophy in cachexia involves tumor-derived cytokines, including TNF $\alpha$, IL-1, and IL-6. Upon interaction with their unique receptors on skeletal muscle, these cytokines activate NF-kappaB, a transcription factor crucial for atrophy related sarcomere proteolysis to occur. The significance of NF- $\mathrm{kB}$ is highlighted in studies demonstrating that genetic inhibition of NF- $\mathrm{kB}$ ameliorates cancer-induced muscle loss in vivo. In the present study, we evaluate a selective NF-kappaB inhibitor (NBD peptide) which targets the IkappaB complex to prevent cancer-induced skeletal muscle atrophy in an established mouse model (C26 adenocarcinoma). We identified for the first time that NBD peptide can directly inhibit tumor-induced NFkappaB activation in skeletal muscle, resulting in a decrease loss of lean muscle. We also identified that NBD peptide reduces the expression of the tumor induced ubiquitin ligases MuRF-1 and MAFbx/Atrogin-1 necessary for atrophy. These findings highlight that NBD peptide may be a potential selective therapeutic agent for the treatment of cancer cachexia.
\end{abstract}

Keywords: Cachexia; NF-kappa-B; Muscle atrophy; Cancer; NBD peptide

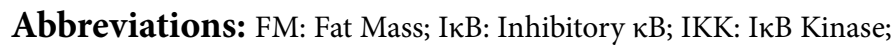
LBM: Lean Body Mass; MuRF1: Muscle Ring Finger-1; MAFBx: Muscle Atrophy F-Box also called Atrogin-1; NBD: NEMO Binding Domain; NEMO: NF-kB Essential Modulator; NF-kB: Nuclear Factor-kappa B

\section{Introduction}

Cancer cachexia is a severe wasting syndrome characterized by the progressive loss of skeletal muscle and an increase in systemic inflammation. This highly debilitating condition is also associated with weight loss, depletion of fat stores, anemia, insulin resistance, and alterations in carbohydrate, lipid, and protein metabolism $[7,30]$. Cachexia is seen in as many as $80 \%$ of patients with advanced malignancy and, rather than tumor burden, accounts for an estimated 20 to $30 \%$ of all cancer related deaths $[30,37,65]$. Tumor-induced wasting also lowers patient response to chemotherapy, corresponding to a poorer prognosis and quality of life [20]. Despite the clinical significance of the problem, effective therapies targeting skeletal muscle loss in cancer cachexia are not currently available. The good news is that a number of studies have identified that tumor derived pro-inflammatory cytokines as the major mechanism involved in inducing muscle atrophy [6]. This allows the testing and development of rationale drug therapies, as in the present study.

Cancer cachexia diminishes lean body mass in response to increases in TNFa, IL-1, and IL-6 $[17,49]$. These tumor derived and locally produced cytokines interact with their cognate receptors on skeletal muscle to activate the NF- $\kappa \mathrm{B}$ transcription factor, which induces atrophy by activating the ubiquitin proteasome system to degrade the sarcomere $[1,3-5,13,16,24-27,29,38,49,56,66,74,80]$. The significance of the convergence of these signaling pathways on NF- $\kappa \mathrm{B}$ in cancerrelated muscle atrophy has been shown experimentally in a number of different ways. Both genetic or pharmacologic inhibition of NF- $\kappa B$ prevents muscle mass loss, improves strength, and increases muscle regeneration $[2,9,16,28,31,36,46,48,57,70,75]$. These numerous studies implicate NF- $\mathrm{KB}$ as having much potential as a therapeutic target in cancer-induced muscle loss.

Recent studies have reported novel therapeutic interventions which specifically target acute increases in NF- $\mathrm{KB}$, while not affecting the necessary basal NF- $\kappa \mathrm{B}$ activity in cells, including NBD peptide. These interventions target the activation of the IкB kinase (IKK) complex that

*Corresponding author: Monte S. Willis, M.D., Ph.D, Assistant Professor Department of Pathology \& Laboratory Medicine, McAllister Heart Institute, University of North Carolina, Medical Biomolecular Research Building, Rm 2336, 103 Mason Farm Road, Chapel Hill, NC, USA, Tel: (919) 843-1938; Fax: (919) 843 4585; E-mail: monte willis@med.unc.edu

Received October 22, 2010; Accepted November 17, 2010; Published December 15,2010

Citation: Wysong A, Asher SA, Yin X, Gore MR, Weinstein L, et al. (2011) Selective Inhibition of NF-kappa-B with NBD Peptide Reduces Tumor-Induced Wasting in a Murine Model of Cancer Cachexia In vivo. J Cancer Sci Ther 3: 022-029. doi:10.4172/1948-5956.1000052

Copyright: ( 2011 Wysong A, et al. This is an open-access article distributed under the terms of the Creative Commons Attribution License, which permits unrestricted use, distribution, and reproduction in any medium, provided the original author and source are credited. 
Citation: Wysong A, Asher SA, Yin X, Gore MR, Weinstein L, et al. (2011) Selective Inhibition of NF-kappa-B with NBD Peptide Reduces TumorInduced Wasting in a Murine Model of Cancer Cachexia In vivo. J Cancer Sci Ther 3: 022-029. doi:10.4172/1948-5956.1000052

phosphorylates NF- $\mathrm{KB}$ during its activation. In the present study, we test a competitive inhibitor of the IKK complex (NBD peptide) for its utility in preventing cancer-induced skeletal muscle atrophy for the first time using an established mouse model of cancer cachexia.

\section{Materials and Methods}

\section{Cell lines}

The transplantable C26 adenocarcinoma cells were maintained as monolayers in culture dishes at $37^{\circ} \mathrm{C}$ with $5 \% \mathrm{CO}_{2}$ in a culture medium consisting of Roswell Park Memorial Institute (RPMI) 1640 (Gibco; Rockville, MD) supplemented with 5\% fetal bovine (Hyclone; Logan, UT) and 1\% penicillin/streptomycin (Gibco; Rockville, MD). Prior to injection, cells were harvested at approximately $80 \%$ confluence, washed, and resuspended in phosphate-buffered saline (PBS) at a concentration of $1 \times 10^{7}$ cells per milliliter.

\section{Animals and tumor implantation}

Sixty-five male BALB/c mice aged 43 to 63 days old (weight 22 to 24 grams) were obtained from the Charles River Laboratories (Wilmington, MA). Mice were evenly and randomly divided into groups: healthy control mice, tumor-bearing mice, and tumor-bearing plus NBD peptide $(80 \mu \mathrm{g}, 200 \mu \mathrm{g}$, or $500 \mu \mathrm{g})$. Mice were housed five animals per cage in a temperature controlled room on a 12 hour lightdark cycle. All animals had access to unlimited food and water. Mice were allowed to acclimate to their new environment for approximately 3 days prior to beginning the study.

On day 0 , the mice in tumor-bearing groups were injected subcutaneously in the right flank with $100 \mu \mathrm{L}$ (approximately 500,000 cells) of C26 adenocarcinoma cells. Body weight, tumor volume, and food consumption were measured every other day from inoculation to completion of the study. Beginning on day 6 , untreated tumor-bearing mice received daily single intraperitoneal injections of sterile DMSO while treated tumor-bearing mice received injections of NBD peptide at $80 \mu \mathrm{g}, 200 \mu \mathrm{g}$, or $500 \mu \mathrm{g}$. On day 17 when tumor-bearing mice had a significant tumor burden and clinical signs of cachexia were apparent, all animals underwent body composition analysis using magnetic resonance imagining (MRI). A final total body weight measurement was also obtained. Tumors were resected, measured, and weighed and total carcass weight (total body weight-tumor weight) was calculated. Hind limbs were weighed separately. Quadriceps and gastrocnemius muscles, and tumors were excised from each animal immediately after sacrifice, snap frozen in liquid nitrogen and stored at $-80^{\circ} \mathrm{C}$. Liver and kidneys were removed and placed in $10 \%$ formalin preservative for histologic analysis. All animal protocols were reviewed and in compliance with the Institutional Animal Care and Use Committee (IACUC).

\section{Assessment of body weight, carcass weight, tumor size, and food intake}

Tumor weight was measured from gross specimens harvested at the completion of the study. Final carcass weight was calculated by subtracting the excised tumor weight from the total body weight measurement; interval carcass weight was determined by subtracting the fraction of the final tumor weight based on volume of the tumor (relative to final volume of the tumor). Body weight and the tumor dimensions (length (A) and width (B)) were measured every other day. Tumor growth was assessed using calipers in 2 dimensions accurate to $0.1 \mathrm{~mm}$. The volume of the tumor was estimated using the following formula: volume $=\pi / 6 \times \mathrm{A}^{2} \mathrm{~B}$. The weight of the tumors was measured from gross specimens harvested at the completion of the study. For days 0 through 16, the weight of the tumor was determined as a fraction of the final tumor weight based on the measured volume of the tumor. The animals were housed five animals per cage for measurement of food consumption. The amount of food ingested was measured by every other day by taking the daily weights (grams) of food. Mean daily food intake and cumulative intake were determined for each group of mice.

\section{Body composition analysis}

Prior to tumor injection, all animals underwent body composition analysis using magnetic resonance imaging (Lunar PIXImus densitometer, GE Medical Systems). Animals were gently placed in a tube designed for mice $<40 \mathrm{~g}$ and placed in the scanner. All scans were done using the full body mode. Lean body mass (LBM), fat mass (FM), and water weight were measured in each animal. Tumors were found to have the same density as LBM and were subtracted out after weighing the tumors in tumor-bearing animals.

\section{Western blot analysis}

For Western blot analysis, gastrocnemius muscle samples were pulverized, extracted, and solubilized using T-PER Tissue Protein Extraction Reagent (Pierce, Rockford, IL) then centrifuged for 10 minutes at $13,000 \mathrm{x} g$ at $4^{\circ} \mathrm{C}$. The protein-containing supernatant was stored at $-80^{\circ} \mathrm{C}$. After determination of the protein concentration for each sample using Bradford reagent (Bio-Rad), 40 $\mu \mathrm{g}$ of total quadriceps or gastrocnemius muscle protein extracts were separated using NuPAGE Novex $4 \%$ to $12 \%$ bis-Tris gels (Invitrogen). Proteins were transferred to nitrocellulose membranes using I-Blot Gel Transfer (Invitrogen). The membranes were blocked with 5\% dry milk protein (Carnation, Wilkes-Barre, PA), diluted in 1X tris-buffered saline with $0.1 \%$ Tween-20 (TBS-T) and incubated with antibodies of interest diluted in $5 \%$ bovine serum albumin (BSA) diluted in 1X TBS-T or $5 \%$ milk. After washing with TBS-T and labeling with secondary antibodies, light emission after addition of electrochemiluminescence (ECL) detection reagent (GE Healthcare UK Limited, Buckinhamshire, UK) was captured onto X-ray film. Bound antibodies were stripped from membranes by incubation in stripping buffer (Thermo Scientific, Rockford IL). Stripped blots were washed and re-probed with other antibodies of interest. To control for equal loading, all blots were stained with anti-tubulin antibody since the more commonly used actin may be cleaved in these experimental models of muscle wasting.

\section{Antibodies}

Antibodies directed against p65 (1:500), phosphorylated p65 (pp65)(1:500) were purchased from Cell Signaling Technology (Danvers, MA). $\beta$-tubulin antibodies (Santa Cruz Biotechnology, 1:25,000) were used to normalize loading.

\section{Cross-sectional muscle samples}

Hind limbs were harvested from approximately three animals per group at day 17 and placed in $10 \%$ formalin buffered in phosphate (Electron Microscopy Sciences, Hatfield, PA) for approximately 48 hours. Tissue samples were then washed in water and placed in $70 \%$ ethanol. Tissues were sliced in five micrometer sections, placed on slides, and stained with hematoxylin and eosin (H\&E) stain using standard techniques.

\section{Drug toxicity}

Liver and kidney specimens were harvested and immediately placed in $10 \%$ neutral phosphate-buffered formalin for fixation at $4^{\circ} \mathrm{C}$ After approximately 24 hours, blocks were rinsed with water and placed in $70 \%$ ethanol at room temperature. All samples were embedded in paraffin, sliced in 5 micrometer sections and placed on slides. Tissues 
Citation: Wysong A, Asher SA, Yin X, Gore MR, Weinstein L, et al. (2011) Selective Inhibition of NF-kappa-B with NBD Peptide Reduces TumorInduced Wasting in a Murine Model of Cancer Cachexia In vivo. J Cancer Sci Ther 3: 022-029. doi:10.4172/1948-5956.1000052

were stained with $\mathrm{H} \& \mathrm{E}$ staining and evaluated by an independent, blinded pathologist for evidence of drug toxicity.

\section{Total RNA isolation/real time PCR determination of mRNA expression}

Frozen quadriceps muscle tissue samples taken immediately after euthanasia were thawed in Trizol reagent (Sigma Chemical). Total RNA was extracted and purified using the ABI PRISM 6100 Nucleic Acid PrepStation according to the manufacturer's protocols (Applied Biosystems, Foster City, CA). Quantitative mRNA expression was determined using a two step reaction. cDNA was made using the High Capacity cDNA Archive kit (Applied Biosystems). Real time PCR (RTPCR) was amplified on an ABI Prism 7900 HT Sequence Detection system using cDNA and TaqMan probe sets in TaqMan ${ }^{\circ}$ Universal PCR Master Mix. The TaqMan probes used in these studies included MuRF1 (Mm01188690_m1), MAFbx/Atrogin-1/Fbxo32 (Mm00499518_m1), and 18S (Hs99999901_s1) (Applied Biosystems). Data are depicted as mean fold change (MFC) versus the $18 \mathrm{~S}$ expression (non-tumorbearing animals). Three replicate plates and averages were calculated for each treatment group.

\section{Statistical analysis}

Results are presented as the mean \pm standard error throughout the manuscript. The significance of observed differences between groups when greater than 2 groups are present was determined using a one- way analysis of variance (ANOVA) with a repeated measures analysis (using Student's t-test) when the F ratio reached significance $[14,69]$. Analyses were performed using SPSS (SPSS, Inc., Chicago, IL) and basic statistics on Microsoft Excel 2007 (Microsoft, Seattle, WA). Statistical significance was defined as $\mathrm{p}<0.05$.

\section{Results}

\section{C26 adenocarcinoma cells produce tumor-induced wasting in BALB/c mice}

The C26 adenocarcinoma murine model of cancer cachexia was chosen as a model because it has been extensively characterized over the past 30 years to test chemotherapeutics in vivo [8]. C26 adenocarcinoma cells were placed in the right flank of $\mathrm{BALB} / \mathrm{c}$ mice to induce cancer cachexia. Palpable tumors were identified by day 6 after inoculation in experimental mice. Weight loss was detected on approximately day 8 , and on day 17, carcass weights of untreated tumor-bearing mice were $89 \%$ that of healthy controls ( $\mathrm{p}<0.001$ ) (Figure $1 \mathrm{~A}$ ). Untreated tumorbearing mice lost an average of $4 \%$ of their starting body weight, while control mice gained approximately 10\% (Figure 1B). Using MRI for body composition analysis, untreated tumor-bearing mice lost more lean body mass $(20.51 \pm 0.44 \mathrm{~g}$ vs. $19.39 \pm 0.18 \mathrm{~g}, \mathrm{p}=0.02)$ and fat mass $(2.64 \pm 0.11 \mathrm{~g}$ vs. $1.71 \pm 0.27 \mathrm{~g}, \mathrm{p}=0.001)$ than control mice (Figure $1 \mathrm{C})$, despite equivalent food intake among all groups (Figure 1D).

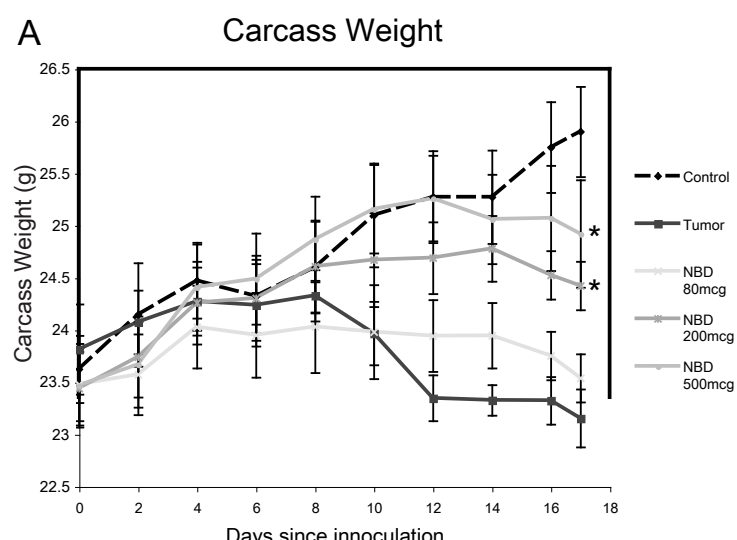

B
C Body Composition (g)

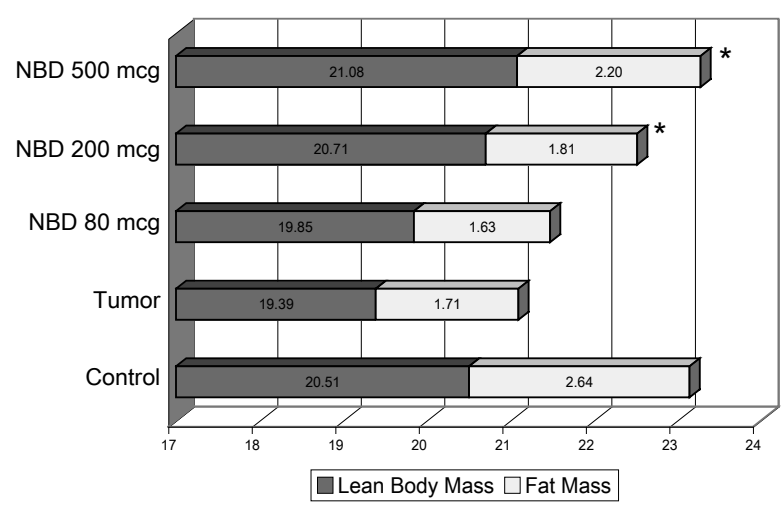

D

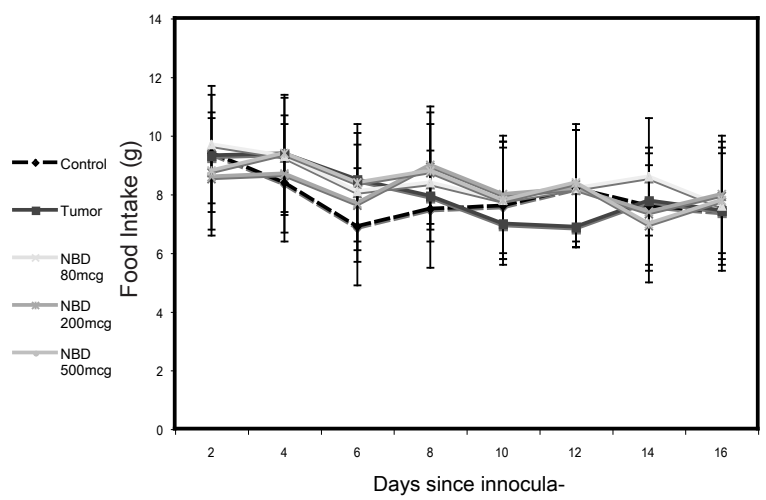

Figure 1: NBD peptide treatment is associated with a reduction in tumor-induced wasting in an experimental model of cancer cachexia. (A) The effects of NBD peptide (injected daily for 11 days) on carcass weight (g). (B) Mean final \% weight loss of each of the five groups. (C) Using MRI for body composition analysis, NBD peptide was associated with a dose response increase in lean body mass and fat mass when compared to untreated tumor-bearing mice on day 17 . (D) There were no significant differences in average daily food intake for each of the five groups. ${ }^{*} p<0.05 .{ }^{*} p<0.001$. 
A

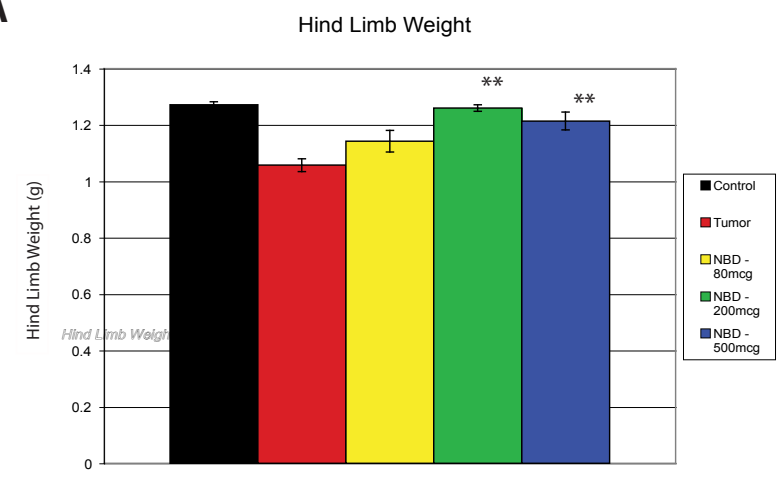

C

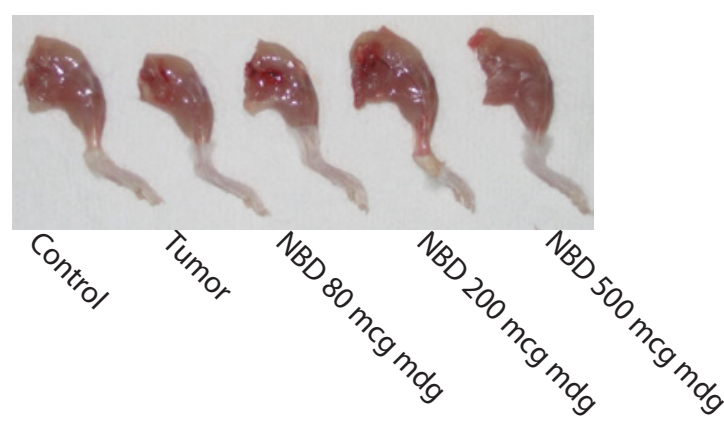

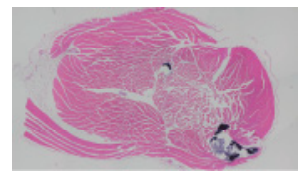
$0.70 \mathrm{~cm} \times 0.48 \mathrm{~cm}$

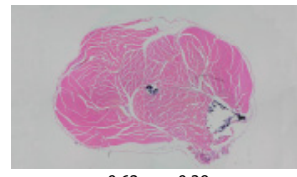

$0.62 \mathrm{~cm} \times 0.39 \mathrm{~cm}$

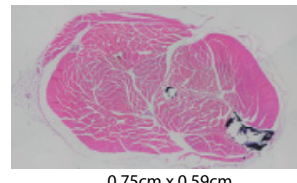

$0.75 \mathrm{~cm} \times 0.59 \mathrm{~cm}$

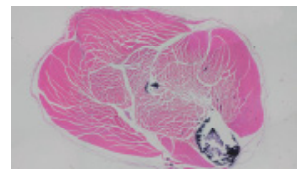

$0.72 \mathrm{~cm} \times 0.49 \mathrm{~cm}$

Figure 2: NBD peptide shows an almost complete reversal of hind limb wasting. (A) Hind limb weights in control, untreated tumor, and NBD peptide treated mice at day 17. (B) Visual differences in hind limb wasting can be appreciated between control, untreated, and treated mice in gross hind limb and (C) H\&E stained transverse sections of the lower leg muscles. (Top to bottom: control, untreated tumor-bearing, tumor-bearing mice treated with $200 \mu \mathrm{g}$, and $500 \mu \mathrm{g}$ of NBD peptide). ${ }^{* *} \mathrm{p}<0.001$.

Nemo-binding domain peptide (NBD) peptides inhibit skeletal muscle NF-kB and reduce tumor-induced weight loss

Tumor-bearing mice treated with $80 \mu \mathrm{g}, 200 \mu \mathrm{g}$, and $500 \mu \mathrm{g}$ of NBD peptide gained $1 \%, 4 \%$, and $6 \%$ of their starting body weight, respectively, compared to untreated tumor-bearing mice who lost $4 \%(\mathrm{p}<0.05)$ (Figure 1A, 1B). Using MRI body composition analysis, tumor-bearing mice treated with NBD peptide had a dose dependent increase in lean body mass (LBM) and fat mass (FM) when compared to untreated tumor-bearing mice (Figure 1C). LBM was $19.39 \pm 0.18$ $\mathrm{g}$ for untreated animals compared to $19.85 \pm 0.44 \mathrm{~g}, 20.71 \pm 0.51 \mathrm{~g}$, and $21.08 \pm 0.53 \mathrm{~g}$ for increasing doses of NBD peptide. FM also increased in animals treated with NBD peptide $1.63 \pm 0.17 \mathrm{~g}, 1.81 \pm 0.21 \mathrm{~g}$, and $2.20 \pm 0.17 \mathrm{~g}$ compared to $1.71 \pm 0.27 \mathrm{~g}$ for untreated tumor-bearing animals. Significant protection against the loss of lean body mass was reached at NBD levels of $200 \mu \mathrm{g}(\mathrm{p}=0.03)$ and $500 \mu \mathrm{g}(\mathrm{p}=0.03)$ and at $500 \mu \mathrm{g}$ for fat mass $(\mathrm{p}=0.04)$. Food intake did not significantly differ across control, untreated or treated tumor-bearing groups (Figure 1D), suggesting that NBD effects were independent of the amount of food that was ingested by each group.

The hind limbs of the mice were weighed immediately after euthanasia to determine differences in muscle mass. Tumor-bearing mice had significant hind limb atrophy when compared to non tumorbearing controls $(1.27 \pm 0.01 \mathrm{~g}$ vs. $1.06 \pm 0.02 \mathrm{~g}, \mathrm{p}<0.001)$ (Figure 2$)$. Hind limb weight was increased in NBD peptide treated animals: $1.14 \pm 0.03$ $\mathrm{g}, 1.26 \pm 0.01 \mathrm{~g}$, and $1.22 \pm 0.03 \mathrm{~g}$ in animals treated with $80 \mu \mathrm{g}, 200 \mu \mathrm{g}$, and $500 \mu \mathrm{g}$ of NBD peptide, respectively $(\mathrm{p}=0.23, \mathrm{p}=0.004, \mathrm{p}<0.001)$. Treatment with NBD peptide at the mid and high doses showed an almost complete reversal of hind limb wasting comparable to control animals with a hind limb weight of $1.27 \pm 0.01 \mathrm{~g}$. Visual differences in hind limb wasting can be appreciated between control, treated, and untreated mice in gross hind limb and $\mathrm{H} \& \mathrm{E}$ stained transverse sections of lower leg muscles (Figure 2B, 2C).

To determine if NBD peptide affected the C26 tumor in vivo, we investigated how NBD affected tumor volume. The groups given daily treatment with $200 \mu \mathrm{g}$ and $500 \mu \mathrm{g}$ NBD had a reduction in final tumor volume compared to untreated tumor-bearing mice $(p=0.02, p=0.03)$ (Supplemental Figure 1). However, significant tumor burden was still present in all tumor-bearing animals. The final weight of the isolated tumors at day 17 according to treatment was: 1 ) Tumor only $1.28 \pm 0.14$ g; 2) NBD $80 \mu$ g 0.86 \pm 0.13 g; 3) NBD $200 \mu$ g 0.67 \pm 0.12 g; and 4) NBD $500 \mu \mathrm{g} 0.70 \pm 0.13 \mathrm{~g}$.

\section{Phosphorylated p65 down regulated with NBD peptide}

To confirm that NBD inhibited NF- $\mathrm{kB}$ activity in our model, we

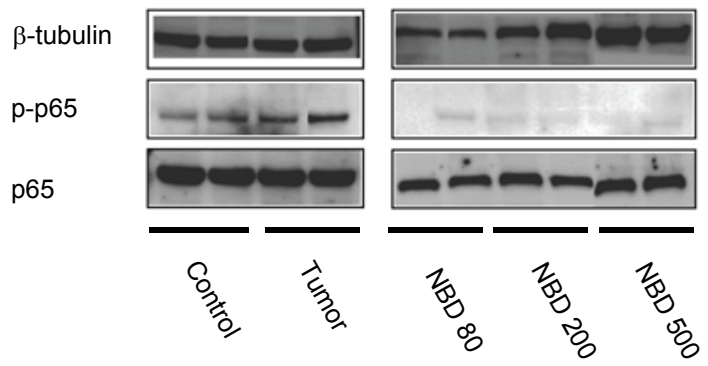

Figure 3: Phosphorylated p65 is down-regulated with NF-kB inhibition using NBD peptide. Gastrocnemius muscles taken from control, tumor-bearing, and NBD peptide treated tumor-bearing animals were homogenized and examined by immunoblots probing for p-p65, p65, and tubulin as a loading control. 
Citation: Wysong A, Asher SA, Yin X, Gore MR, Weinstein L, et al. (2011) Selective Inhibition of NF-kappa-B with NBD Peptide Reduces TumorInduced Wasting in a Murine Model of Cancer Cachexia In vivo. J Cancer Sci Ther 3: 022-029. doi:10.4172/1948-5956.1000052

A

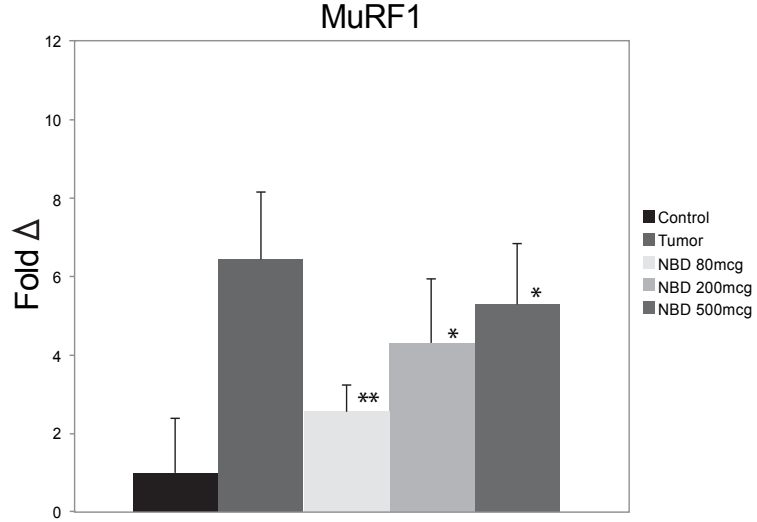

B

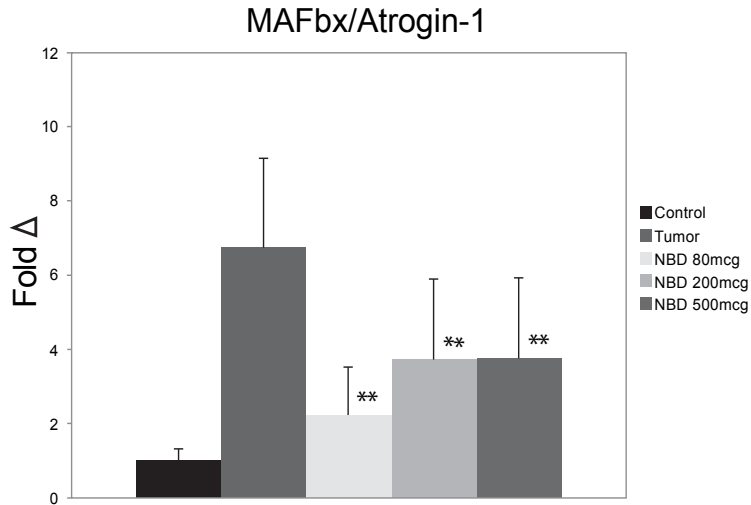

Figure 4: NBD peptide reverses enhanced expression of muscle specific ubiquitin ligases MuRF1 and MAFbx/Atrogin-1 induced in tumor-bearing animals. Using RT-PCR, the loss of lean muscle in tumor-bearing animals was confirmed with the upregulation of MuRF1 (A) and MAFbx/Atrogin-1 (B) shown in fold change relative to non-tumor-bearing control animals. NBD peptide treatment attenuated the tumor-mediated increase in MuRF1 and MAFbx/Atrogin-1 expression. * $p<0.05$. ${ }^{* *} p<0.001$

investigated the amount of active NF- $\mathrm{kB}(\mathrm{p}-\mathrm{p} 65)$ in a representative skeletal muscle, the gastrocnemius. Gastrocnemius was harvested from control, DMSO-injected tumor-bearing and NBD peptide treated tumor-bearing $\mathrm{BALB} / \mathrm{c}$ mice after 17 days and were homogenized and examined by immunoblots probing for p-p65, p65, and tubulin as a loading control. We identified increased NF- $\mathrm{kB}$ activity (i.e. increased p-p65 compared to total p65) in cachectic muscles compared to controls, which was reversed with NF-kB inhibition using NBD peptide
(Figure 3).

\section{Reduced induction of muscle E3 ubiquitin ligases with NF-kB inhibition}

In multiple models of skeletal muscle atrophy, muscle specific ubiquitin ligases MAFbx/Atrogin-1 and MuRF1 have been demonstrated to be upregulated and mediate the induced atrophy [13]. Furthermore, they are increased in response to chronic NF- $\mathrm{kB}$ activation [16]. Therefore, we quantitatively determined MuRF1 and MAFbx/Atrogin-1 mRNA expression in quadriceps from each animal from all the groups investigated. As expected, we identified that tumors significantly increased MuRF1 and MAFbx/Atrogin-1 levels relative to non tumor-bearing control animals approximately $6.7-$ and 6.1fold, respectively (Figure 4). NBD treatment of tumor-challenged mice significantly decreased expression of both MuRF1 and MAFbx/ Atrogin-1, suggesting that NBD-inhibition of NF- $\kappa B$ acted to inhibited skeletal muscle atrophy by down-regulating the ubiquitin ligases previously shown to be pivotal in medicating atrophy.

\section{NBD peptide treatment showed no evidence of drug induced toxicity at the levels used in this study}

Recent studies have reported the use of NBD peptide therapy for the treatment of colitis and arthritis in mouse models without any evidence of toxicity [22,61]. Similarly, in the present study, we did not identify any toxicity as a result of treatment of NBD peptide, including any lethality or acute and chronic effects on behavior after daily injection of NBD peptide up to $500 \mu \mathrm{g}$ per mouse. At the end of the study, we carefully looked for morphological evidence of toxicity and did not find any. No hepatotoxicity or nephrotoxicity across all doses of NBD peptide delivery were found, as confirmed by a blinded, independent pathologist and shown in Figure 5.

\section{Discussion}

The $\mathrm{C} 26$ adenocarcinoma murine model of cancer-induced cachexia was created in 1975 as a model to test biological and chemotherapeutics in vivo [19]. Since then, nearly 190 manuscripts have been written using the C26 adenocarcinoma cell line, which delineate the natural history of cachexia and its underlying mechanisms [8]. When placed in mice, the C26 adenocarcinoma cell line form tumors which secrete proinflammatory cytokines. IL- 6 was initially identified as a prominent player in C26-induced cachexia using anti-IL-6 antibodies, but later studies also identified TNF $\alpha$ and IL-1 [32,76], paralleling human cancer cachexia [17]. While all these cytokines interact with their own unique receptors on striated muscle, each receptor converges on the activation

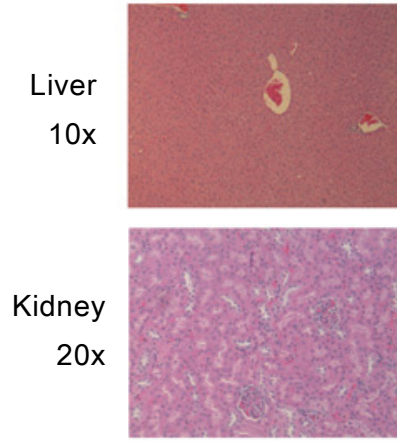

Control
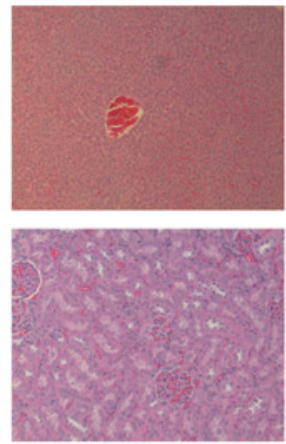

Tumor
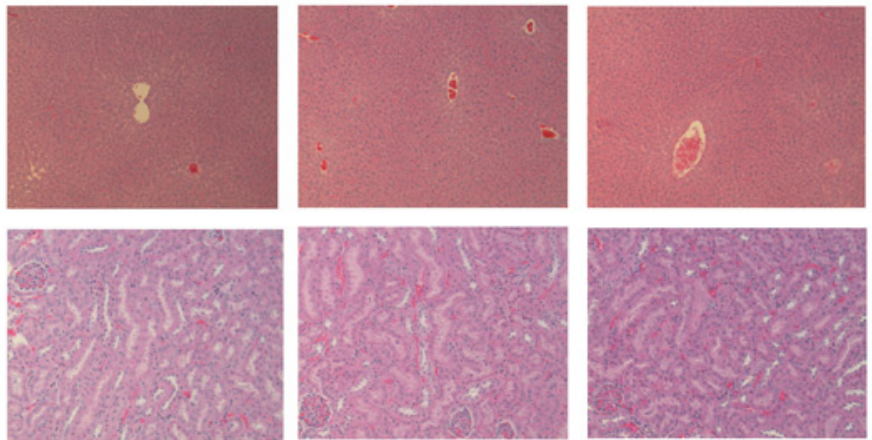

NBD $80 \mathrm{mcg}$

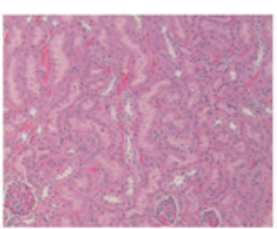

NBD 200mcg

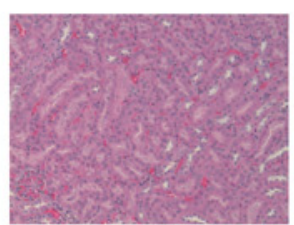

NBD 500mcg

Figure 5: NBD peptide treatment does not result in drug-induced hepatotoxicity or nephrotoxicity. Representative microscopic images of liver and kidney sections stained with H\&E from either control mice, untreated tumor-bearing mice or tumor-bearing mice injected daily with $80 \mu \mathrm{g}, 200 \mu \mathrm{g}$, or $500 \mu \mathrm{g}$ of NBD peptide. 
of the transcription factor NF- $\mathrm{KB}$ to induce skeletal muscle atrophy. $\mathrm{NF \kappa B}$ induces proteolyisis via the ubiquitin proteasome system, including increases in the ubiquitin ligases MuRF1 and MAFbx/ Atrogin-1, which specifically interact with sarcomere proteins and mediate their degradation directly [16,67].

The activation of the Inhibitor $\kappa \mathrm{B}$ Kinase complex (IKK) is central to NF- $\kappa \mathrm{B}$ activation. Phosphorylation of IкB proteins by the IKK complex is a critical regulatory step in proinflammatory signaling pathways leading to NF- $\mathrm{kB}$ activation [41]. The IKK complex contains two catalytic subunits (IKK- $\alpha$ and IKK- $\beta$ ) and a regulatory component, NF-kB essential modulator (NEMO or IKK- $\gamma$ ) [34]. The IKK complex phosphorylates the $\mathrm{IkBa}$, which is then targeted by the ubiquitin proteasome system for degradation, allowing NF- $\kappa B$ to translocate to the nucleus. The NBD peptide used in this study potently inhibits stress-induced NF- $\kappa B$ activation without affecting basal NF- $\kappa B$ activity [45], by competitively inhibiting the IKK complex from forming. Specifically, the NBD peptide prevents the IKKgamma (NEMO) from forming its interaction with IKK $\beta$ by competitive inhibition [45]. This mechanism is distinct from other NF- $\mathrm{KB}$ inhibitor strategies, such as proteasome inhibition, because it doesn't affect the necessary basal proteasome activity vital to protein quality control $[47,50,71,72]$. This peptide has been used successfully in diminishing inflammatory responses in several animal models of disease, including inflammatory bowel disease $[2,18,21,36,55]$.

In the present study, we demonstrate for the first time that selective inhibition of NF- $\mathrm{\kappa B}$ using a cell permeable peptide to block the NEMO domain of the I $\kappa \mathrm{B}$ complex is able to inhibit skeletal muscle atrophy. We also identified that NBD peptide inhibits the C26 tumor-induced increases in the ubiquitin ligases MuRF1 and MAFbx/Atrogin-1. MuRF1 and MAFbx/Atrogin-1 expression were investigated because of their upregulation during skeletal muscle atrophy, and their necessary role in mediating skeletal muscle atrophy in different experimental models [13]. Recent studies have implicated that NF- $\kappa B$ regulates both MuRF1 and MAFbx/Atrogin-1 [16,33], making it plausible that NF$\kappa \mathrm{B}$ inhibition is preventing the up regulation of these ubiquitin ligases fundamental in skeletal muscle atrophy [13]. However, MuRF1 and MAFbx/Atrogin-1 have been reported to be regulated by the FOXO transcription factors as well as NF- $\kappa B[54,58,68]$. Additional studies will be needed to determine the role of MuRF1 and MAFbx/Atrogin-1 in cancer cachexia to delineate this relationship between MuRF1 and MAFbx/Atrogin-1 expression regulation and their actual role in the skeletal muscle atrophy process.

In the present study, both the 200 and $500 \mu \mathrm{g}$ of NBD inhibited both the C26 tumor growth AND prevented lean body mass and fat mass loss, skeletal muscle NF- $\mathrm{kB}$ signaling, and MuRF1/Atrogin-1 expression. While this indicates the NBD may have clinical utility in vivo in a clinically relevant model, it does not allow the differentiation of the 2 possible mechanisms by which it may be protective. The protection against skeletal muscle injury may either be direct, due to the cytokine mediated NF- $\mathrm{kB}$ inhibition at the muscle and adipocyte itself. However, it is possible that the protective effects of NBD may be indirect, due to its inhibition of the tumor growth itself. This is an important point to make because the dysregulation of NF- $\mathrm{kB}$ signaling is a major driver of cancer [53] and its inhibition has been shown experimentally to prevent oncogenic initiation and progression [10]. However, the magnitude between the tumor size inhibition $(\sim 30 \%$, Supplemental Figure 1) and the skeletal muscle protection ( $5 \%$, Figure 2) are mismatched, suggesting that inhibition at the skeletal muscle may be prominent, although both mechanisms may be in play in the model tested.
There are few therapies currently available to treat cancer cachexia. They include mainly appetite stimulants and anabolic agents such as prednisolone $[15,51]$ and progesterone $[12,42,43,77]$ and ghrelin, a ligand which stimulates growth hormone release [44,59]. Anecdotally, the use of $\alpha-3$ omega fatty acids (eicosapentaenoic acid) [52] and thalidomide (potent anti-TNF activity) have been reported [48]. Experimentally, glucocorticoids, aspirin [63], indomethacin [35,79], methotrexate [60], and celecoxib [23], all have been shown to have some efficacy, which are believed to be effective, in part, due to their ability to inhibit NF-kB activity $[10,32,73,78]$. However, these agents are neither potent nor selective for the NF-kB pathway. In addition, they have many off-target side effects. In the present study, using a specific inhibitor of the IкB Kinase complex, we did not find evidence of toxicity to the liver or kidney across all three doses of NBD peptide. These results parallel those of Jimi et al. [39], who treated daily with NBD peptide for several weeks in a murine model of rheumatoid arthritis.

The discordance in absolute carcass weight and the total weight determined by quantitative magnetic resonance (QMR) in Figure 1A and Figure 1C has been previously identified and is largely due to the QMR methodology. Until recently, Dual X-Ray Absorptiometry (DEXA) scans have been largely utilized to determine body composition. However, recent publications comparing QMR to DEXA in mice highlight some of the advantages and caveats of using QMR [64]. QMR is more precise than DEXA in determining body composition and could be performed in non-anesthetized mice [64]. This is the reason that we chose QMR for our current studies. In fact, the precision of QMR in these studies allowed us to determine that the higher two doses of NBD peptide could prevent both the lean muscle and fat mass loss induced by tumor (Figure 1C). However, while QMR more precise, it's estimation of lean mass is underestimated because, in part, it does not accurately measure water bound in tissues. In fact, rodent studies have found a very high correlation between QMR and carcass weights. QMR was found to overestimate fat mass and underestimate lean mass and total water [40]. Despite these absolute differences in QMR values and carcass weights, the measure of fat, lean, and water were highly correlated with the chemical analyses of these $\left(r^{2}>0.99\right)$ [40].

Although it is generally believed that treating cachexia will not cure the underlying neoplastic process, reversal of wasting may improve treatment response, prolong survival, and improve quality of life. Of note, an attenuation of tumor growth at the highest doses of NBD peptide was seen in our experiment. However, this cannot be the sole reason for the reversal of the wasting as beneficial effects on cachexia were seen at the lowest dose where tumor growth was not significantly different than untreated tumor-bearing animals. In addition, there was still a significant tumor burden present in animals treated at the highest doses.

Our findings suggest that inhibiting NF- $\kappa \mathrm{B}$ by targeting the I $\kappa \mathrm{B}$ Kinase complex is able to ameliorate tumor-induced muscle wasting and significantly reduces weight loss through inhibition of NF- $\mathrm{kB}$ activity and decreased expression of muscle atrophy genes. These preclinical studies highlight the therapeutic potential of the NBD peptide therapy, which may prove to be a potent and safe therapeutic agent in cancer cachexia.

\section{Acknowledgements}

The authors wish to acknowledge the assistance of Janice Weaver in the Animal Histopathology Laboratory at the University of North Carolina for assistance in preparing histological specimens. We are also grateful for the assistance of Dr Hyung-Suk Kim from the University of North Carolina Department of Pathology \& Laboratory Medicine's Animal Clinical Chemistry and Gene Expression Laboratory for his assistance with the real time PCR experiments. 
Citation: Wysong A, Asher SA, Yin X, Gore MR, Weinstein L, et al. (2011) Selective Inhibition of NF-kappa-B with NBD Peptide Reduces TumorInduced Wasting in a Murine Model of Cancer Cachexia In vivo. J Cancer Sci Ther 3: 022-029. doi:10.4172/1948-5956.1000052

\section{Grant support}

A.W. was supported by the Howard Hughes Medical Institute Research Training Fellowship. This work was supported by University of North Carolina Program in Translational Science Grant (to M.C.), the American Heart Association Scientist Development Grant (to M.W.), and the National Heart, Lung, and Blood Institute grant R01HL104129 (to M.W.).

\section{References}

1. Acharyya S, Butchbach ME, Sahenk Z, Wang H, Saji M, et al. (2005) Dystrophin glycoprotein complex dysfunction: a regulatory link between muscular dystrophy and cancer cachexia. Cancer Cell 8: 421-432.

2. Acharyya S, Villalta SA, Bakkar N, Bupha-Intr T, Janssen PM, et al. (2007) Interplay of IKK/NF-kappaB signaling in macrophages and myofibers promotes muscle degeneration in Duchenne muscular dystrophy. J Clin Invest 117: 889901.

3. Anker SD, von Haehling S (2004) Inflammatory mediators in chronic heart failure: an overview. Heart 90: 464-470.

4. Anker SD, Negassa A, Coats AJ, Afzal R, Poole-Wilson PA, et al. (2003) Prognostic importance of weight loss in chronic heart failure and the effect of treatment with angiotensin-converting-enzyme inhibitors: an observational study. Lancet 361: 1077-1083.

5. Anker SD, Ponikowski PP, Clark AL, Leyva F, Rauchhaus M, et al. (1999) Cytokines and neurohormones relating to body composition alterations in the wasting syndrome of chronic heart failure. Eur Heart J 20: 683-693.

6. Argilés JM, Busquets S, López-Soriano FJ (2005) The pivotal role of cytokines in muscle wasting during cancer. Int J Biochem Cell Biol 37: 2036-2046.

7. Argilés JM, Moore-Carrasco R, Fuster G, Busquets S, López-Soriano FJ (2003) Cancer cachexia: the molecular mechanisms. Int J Biochem Cell Biol 35: 405-409.

8. Aulino P, Berardi E, Cardillo VM, Rizzuto E, Perniconi B, et al. (2010) Molecular, cellular and physiological characterization of the cancer cachexia-inducing C26 colon carcinoma in mouse. BMC Cancer 10: 363

9. Barber MD, Ross JA, Voss AC, Tisdale MJ, Fearon KC (1999) The effect of an oral nutritional supplement enriched with fish oil on weight-loss in patients with pancreatic cancer. $\mathrm{Br} \mathrm{J}$ Cancer 81: 80-86.

10. Barnes PJ (2006) Corticosteroid effects on cell signalling. Eur Respir J 27: 413426.

11. Bassères DS, Baldwin AS (2006) Nuclear factor-kappaB and inhibitor of kappaB kinase pathways in oncogenic initiation and progression. Oncogene 25: $6817-6830$

12. Berenstein EG, Ortiz Z (2005) Megestrol acetate for the treatment of anorexiacachexia syndrome. Cochrane Database Syst Rev CD004310.

13. Bodine SC, Latres E, Baumhueter S, Lai VK, Nunez L, et al. (2001) Identification of ubiquitin ligases required for skeletal muscle atrophy. Science 294: 17041708.

14. Bremer M (2010) Statistics at the bench: a step-by-step handbook for biologists, 1st edn (Cold Spring Harbor: Cold Spring Harbor Laboratory Press).

15. Bruera E, Roca E, Cedaro L, Carraro S, Chacon R (1985) Action of oral methylprednisolone in terminal cancer patients: a prospective randomized double-blind study. Cancer Treat Rep 69: 751-754.

16. Cai D, Frantz JD, Tawa NE Jr, Melendez PA, Oh BC, et al. (2004) IKKbeta/NFkappaB activation causes severe muscle wasting in mice. Cell 119: 285-298.

17. Carson JA, Baltgalvis KA (2010) Interleukin 6 as a key regulator of muscle mass during cachexia. Exerc Sport Sci Rev 38: 168-176.

18. Clohisy JC, Yamanaka Y, Faccio R, Abu-Amer Y (2006) Inhibition of IKK activation, through sequestering NEMO, blocks PMMA-induced osteoclastogenesis and calvarial inflammatory osteolysis. J Orthop Res 24: 1358-1365.

19. Corbett TH, Griswold DP Jr, Roberts BJ, Peckham JC, Schabel FM Jr (1975) Tumor induction relationships in development of transplantable cancers of the colon in mice for chemotherapy assays, with a note on carcinogen structure. Cancer Res 35: 2434-2439.

20. Couch M, Lai V, Cannon T, Guttridge D, Zanation A, et al. (2007) Cancer cachexia syndrome in head and neck cancer patients: part I. Diagnosis, impact on quality of life and survival, and treatment. Head Neck 29: 401-411.
21. Dai S, Hirayama T, Abbas S, Abu-Amer Y (2004) The IkappaB kinase (IKK) inhibitor, NEMO-binding domain peptide, blocks osteoclastogenesis and bone erosion in inflammatory arthritis. J Biol Chem 279: 37219-37222.

22. Davé SH, Tilstra JS, Matsuoka K, Li F, Karrasch T, et al. (2007) Amelioration of chronic murine colitis by peptide-mediated transduction of the IkappaB kinase inhibitor NEMO binding domain peptide. J Immunol 179: 7852-7859.

23. Davis TW, Zweifel BS, O'Neal JM, Heuvelman DM, Abegg AL, et al. (2004) Inhibition of cyclooxygenase-2 by celecoxib reverses tumor-induced wasting. Pharmacol Exp Ther 308: 929-934.

24. Drott C, Lundholm K (1990) Glucose uptake and amino acid metabolism in perfused hearts from tumor-bearing rats. J Surg Res 49: 62-68.

25. Drott C, Ekman L, Holm S, Waldenström A, Lundholm K (1986) Effects of tumor-load and malnutrition on myocardial function in the isolated working rat heart. J Mol Cell Cardiol 18: 1165-1176.

26. Drott C, Waldenström A, Lundholm K (1987) Cardiac sensitivity and responsiveness to beta-adrenergic stimulation in experimental cancer and undernutrition. J Mol Cell Cardiol 19: 675-683.

27. Durham WJ, Dillon EL, Sheffield-Moore M (2009) Inflammatory burden and amino acid metabolism in cancer cachexia. Curr Opin Clin Nutr Metab Care 12: $72-77$.

28. Eley HL, Russell ST, Tisdale MJ (2007) Attenuation of muscle atrophy in murine model of cachexia by inhibition of the dsRNA-dependent protein kinase. Br J Cancer 96: 1216-1222.

29. El-Menyar AA (2008) Cytokines and myocardial dysfunction: state of the art. J Card Fail 14: 61-74.

30. Fearon KC, Carter DC (1988) Cancer cachexia. Ann Surg 208: 1-5.

31. Fischer D, Gang G, Pritts T, Hasselgren PO (2000) Sepsis-induced muscle proteolysis is prevented by a proteasome inhibitor in vivo. Biochem Biophys Res Commun 270: 215-221.

32. Fujita J, Tsujinaka T, Yano M, Ebisui C, Saito H, et al. (1996) Anti-interleukin-6 receptor antibody prevents muscle atrophy in colon-26 adenocarcinomabearing mice with modulation of lysosomal and ATP-ubiquitin-dependent proteolytic pathways. Int J Cancer 68: 637-643.

33. Glass DJ (2005) Skeletal muscle hypertrophy and atrophy signaling pathways Int J Biochem Cell Biol 37: 1974-1984.

34. Hayden MS, Ghosh S (2004) Signaling to NF-kappaB. Genes Dev 18: 2195 2224

35. Hitt A, Graves E, McCarthy DO (2005) Indomethacin preserves muscle mas and reduces levels of E3 ligases and TNF receptor type 1 in the gastrocnemius muscle of tumor-bearing mice. Res Nurs Health 28: 56-66.

36. Hunter RB, Kandarian SC (2004) Disruption of either the Nfkb1 or the Bcl3 gene inhibits skeletal muscle atrophy. J Clin Invest 114: 1504-1511.

37. Inagaki J, Rodriguez V, Bodey GP (1974) Proceedings: Causes of death in cancer patients. Cancer 33: 568-573.

38. Jankowska EA, von Haehling S, Czarny A, Zaczynska E, Kus A, et al. (2005) Activation of the NF-kappaB system in peripheral blood leukocytes from patients with chronic heart failure. Eur J Heart Fail 7: 984-990.

39. Jimi E, Aoki K, Saito H, D'Acquisto F, May MJ, et al. (2004) Selective inhibition of NF-kappa B blocks osteoclastogenesis and prevents inflammatory bone destruction in vivo. Nat Med 10: 617-624.

40. Johnson MS, Smith DL, Nagy TR (2009) Validation of quantitative magnetic resonance (QMR) for determination of body composition in rats. Int J Body Compos Res 7: 99-107.

41. Karin M, Delhase M (2000) The I kappa B kinase (IKK) and NF-kappa B: key elements of proinflammatory signalling. Semin Immunol 12: 85-98.

42. Loprinzi CL, Ellison NM, Schaid DJ, Krook JE, Athmann LM, et al. (1990) Controlled trial of megestrol acetate for the treatment of cancer anorexia and cachexia. J Natl Cancer Inst 82: 1127-1132.

43. Loprinzi CL, Kugler JW, Sloan JA, Mailliard JA, Krook JE, et al. (1999) Randomized comparison of megestrol acetate versus dexamethasone versus fluoxymesterone for the treatment of cancer anorexia/cachexia. J Clin Oncol 17: 3299-3306

44. Lundholm K, Gunnebo L, Körner U, Iresjö BM, Engström C, et al. (2010) Effects by daily long term provision of ghrelin to unselected weight-losing cance patients: a randomized double-blind study. Cancer 116: 2044-2052. 
Citation: Wysong A, Asher SA, Yin X, Gore MR, Weinstein L, et al. (2011) Selective Inhibition of NF-kappa-B with NBD Peptide Reduces TumorInduced Wasting in a Murine Model of Cancer Cachexia In vivo. J Cancer Sci Ther 3: 022-029. doi:10.4172/1948-5956.1000052

45. May MJ, D'Acquisto F, Madge LA, Glöckner J, Pober JS, et al. (2000) Selective inhibition of NF-kappaB activation by a peptide that blocks the interaction of NEMO with the IkappaB kinase complex. Science 289: 1550-1554.

46. McMillan DC, Wigmore SJ, Fearon KC, O'Gorman P, Wright CE, et al. (1999) A prospective randomized study of megestrol acetate and ibuprofen in gastrointestinal cancer patients with weight loss. Br J Cancer 79: 495-500.

47. Mearini G, Schlossarek S, Willis MS, Carrier L (2008) The ubiquitin-proteasome system in cardiac dysfunction. Biochim Biophys Acta 1782: 749-763.

48. Mourkioti F, Kratsios P, Luedde T, Song YH, Delafontaine P, et al. (2006) Targeted ablation of IKK2 improves skeletal muscle strength, maintains mass, and promotes regeneration. J Clin Invest 116: 2945-2954

49. Pajak B, Orzechowska S, Pijet B, Pijet M, Pogorzelska A, et al. (2008) Crossroads of cytokine signaling--the chase to stop muscle cachexia. J Physio Pharmacol 59 Suppl 9: 251-264.

50. Patterson C, Ike C, Willis PW 4th, Stouffer GA, Willis MS (2007) The bitter end: the ubiquitin-proteasome system and cardiac dysfunction. Circulation 115: 1456-1463.

51. Popiela T, Lucchi R, Giongo F (1989) Methylprednisolone as palliative therapy for female terminal cancer patients. The Methylprednisolone Female Preterminal Cancer Study Group. Eur J Cancer Clin Oncol 25: 1823-1829.

52. Price SA, Tisdale MJ (1998) Mechanism of inhibition of a tumor lipid-mobilizing factor by eicosapentaenoic acid. Cancer Res 58: 4827-4831.

53. Razani B, Cheng G (2010) NF-kappaB: much learned, much to learn. Sci Signal 3: pe29.

54. Sacheck JM, Ohtsuka A, McLary SC, Goldberg AL (2004) IGF-I stimulates muscle growth by suppressing protein breakdown and expression of atrophyrelated ubiquitin ligases, atrogin-1 and MuRF1. Am J Physiol Endocrinol Metab 287: E591-E601.

55. Shibata W, Maeda S, Hikiba Y, Yanai A, Ohmae T, et al. (2007) Cutting edge: The IkappaB kinase (IKK) inhibitor, NEMO-binding domain peptide, blocks inflammatory injury in murine colitis. J Immunol 179: 2681-2685.

56. Sjöström M, Wretling ML, Karlberg I, Edén E, Lundholm K (1987) Ultrastructural changes and enzyme activities for energy production in hearts concomitant with tumor-associated malnutrition. J Surg Res 42: 304-313.

57. Smith HJ, Wyke SM, Tisdale MJ (2004) Mechanism of the attenuation of proteolysis-inducing factor stimulated protein degradation in muscle by betahydroxy-beta-methylbutyrate. Cancer Res 64: 8731-8735

58. Stitt TN, Drujan D, Clarke BA, Panaro F, Timofeyva Y, et al. (2004) The IGF1/PI3K/Akt pathway prevents expression of muscle atrophy-induced ubiquitin ligases by inhibiting FOXO transcription factors. Mol Cell 14: 395-403.

59. Strasser F, Lutz TA, Maeder MT, Thuerlimann B, Bueche D, et al. (2008) Safety, tolerability and pharmacokinetics of intravenous ghrelin for cancer-related anorexia/cachexia: a randomised, placebo-controlled, double-blind, doublecrossover study. Br J Cancer 98: 300-308.

60. Tanaka K, Urata N, Mikami M, Ogasawara M, Matsunaga T, et al. (2007) Effect of iguratimod and other anti-rheumatic drugs on adenocarcinoma colon 26-induced cachexia in mice. Inflamm Res 56: 17-23.

61. Tas SW, Vervoordeldonk MJ, Hajji N, May MJ, Ghosh S, et al. (2006) Local treatment with the selective IkappaB kinase beta inhibitor NEMO-binding domain peptide ameliorates synovial inflammation. Arthritis Res Ther 8: R86.
62. Tegeder I, Pfeilschifter J, Geisslinger G (2001) Cyclooxygenase-independent actions of cyclooxygenase inhibitors. FASEB J 15: 2057-2072.

63. Tessitore L, Costelli P, Baccino FM (1994) Pharmacological interference with tissue hypercatabolism in tumour-bearing rats. Biochem J 299: 71-78.

64. Tinsley FC, Taicher GZ, Heiman ML (2004) Evaluation of a quantitative magnetic resonance method for mouse whole body composition analysis. Obes Res 12: 150-160.

65. Tisdale MJ (2002) Cachexia in cancer patients. Nat Rev Cancer 2: 862-871.

66. Tisdale MJ (2009) Mechanisms of cancer cachexia. Physiol Rev 89: 381-410.

67. Vallabhapurapu S, Karin M (2009) Regulation and function of NF-kappaB transcription factors in the immune system. Annu Rev Immunol 27: 693-733.

68. Waddell DS, Baehr LM, van den Brandt J, Johnsen SA, Reichardt HM, et al (2008) The glucocorticoid receptor and FOXO1 synergistically activate the skeletal muscle atrophy-associated MuRF1 gene. Am J Physiol Endocrinol Metab 295: E785-E797.

69. Wagner WE (2010) Using SPSS for social statistics and research methods, 2nd edn (Los Angeles: Pine Forge Press).

70. Wilkinson KD, Smith SE, O'Connor L, Sternberg E, Taggart JJ, et al (1990) A specific inhibitor of the ubiquitin activating enzyme: synthesis and characterization of adenosyl-phospho-ubiquitinol, a nonhydrolyzable ubiquitin adenylate analogue. Biochemistry 29: 7373-7380.

71. Willis MS, Patterson C (2006) Into the heart: the emerging role of the ubiquitinproteasome system. J Mol Cell Cardiol 41: 567-579.

72. Willis MS, Schisler JC, Portbury AL, Patterson C (2009). Build it up-Tear it down protein quality control in the cardiac sarcomere. Cardiovasc Res 81: 439-448.

73. Wu KK (2003) Aspirin and other cyclooxygenase inhibitors: new therapeutic insights. Semin Vasc Med 3: 107-112.

74. Wyke SM, Tisdale MJ (2005) NF-kappaB mediates proteolysis-inducing factor induced protein degradation and expression of the ubiquitin-proteasome system in skeletal muscle. Br J Cancer 92: 711-721.

75. Wyke SM, Russell ST, Tisdale MJ (2004) Induction of proteasome expression in skeletal muscle is attenuated by inhibitors of NF-kappaB activation. $\mathrm{Br} J$ Cancer 91: 1742-1750.

76. Yasumoto K, Mukaida N, Harada A, Kuno K, Akiyama M, et al. (1995) Molecular analysis of the cytokine network involved in cachexia in colon 26 adenocarcinoma-bearing mice. Cancer Res 55: 921-927.

77. Yavuzsen T, Davis MP, Walsh D, LeGrand S, Lagman R (2005) Systematic review of the treatment of cancer-associated anorexia and weight loss. J Clin Oncol 23: 8500-8511.

78. Yin MJ, Yamamoto Y, Gaynor RB (1998) The anti-inflammatory agents aspirin and salicylate inhibit the activity of I(kappa)B kinase-beta. Nature 396: 77-80.

79. Zhou W, Jiang ZW, Tian J, Jiang J, Li N, et al. (2003) Role of NF-kappaB and cytokine in experimental cancer cachexia. World J Gastroenterol 9: 1567-1570.

80. Zolk O, Schenke C, Sarikas A (2006) The ubiquitin-proteasome system: focus on the heart. Cardiovasc Res 70: 410-421. 